\title{
Role of mixed precipitating cloud systems on the typhoon rainfall
}

\author{
C. J. Pan ${ }^{1}$, K. Krishna Reddy ${ }^{2}$, H. C. Lai $^{3}$, and S. S. Yang ${ }^{1}$ \\ ${ }^{1}$ Institute of Space Science, National Central University, Taiwan \\ ${ }^{2}$ Dept. of Physics, Yogi Vemana University, Kadapa, India \\ ${ }^{3}$ Dept. of Eng. \& Manag. of Advanced Tech., Chang Jung Christian University, Taiwan
}

Received: 21 October 2009 - Accepted: 14 December 2009 - Published: 8 January 2010

\begin{abstract}
L-band wind profiler data are utilized to diagnose the vertical structure of the typhoon precipitating cloud systems in Taiwan. For several typhoons, a pronounced bright band (BB) around $5 \mathrm{~km}$ is commonly observed from the observation. Since strong convection within typhoon circulation may disturb and/or disrupt the melting layer, the BB shall not appear persistently. Hence, an understanding of the vertical structure of the $\mathrm{BB}$ region is important because it holds extensive hydrometeors information on the type of precipitation and its variability. Wind profiler observational results suggest that the mixture of convective and stratiform (embedded type) clouds are mostly associated with typhoons. In the case of one typhoon, BB is appeared around $5.5 \mathrm{~km}$ with embedded precipitation and also BB height of $1 \mathrm{~km}$ higher than ordinary showery precipitation. This is evident from the long-term observations of wind profiler and Tropical Rainfall Measuring Mission. The Doppler velocity profiles show hydrometers (ice/snow) at $6 \mathrm{~km}$ but liquid below $5 \mathrm{~km}$ for typhoons and $4 \mathrm{~km}$ for showery precipitation. In the BB region the melting particles accelerations of $5.8 \mathrm{~ms}^{-1} \mathrm{~km}^{-1}$ and $3.2 \mathrm{~ms}^{-1} \mathrm{~km}^{-1}$ are observed for typhoon and showery precipitation, respectively.
\end{abstract}

Keywords. Meteorology and atmospheric dynamics (Precipitation)

\section{Introduction}

Typhoons in the West Pacific Ocean, where Taiwan Island is located, are equivalent to hurricanes in the west coast of the US originated by the warmer sea temperature in West Pacific Ocean and the southwest monsoons from South China

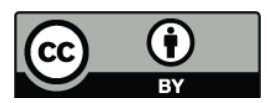

Correspondence to: C. J. Pan

(cjpan@jupiter.ss.ncu.edu.tw)
Sea, there are in general five to ten typhoons affected Taiwan every summer and early autumn. Typhoons are the most serious meteorological phenomena that threaten East Asia and those islands of Cuba, Hispaniola, and Puerto Rico in the Caribbean, as well as Luzon in the northern Philippines (Wu and Kuo, 1999). In 2005, Hurricane Katrina caused severe destruction along the Gulf coast from central Florida to Texas. The most severe loss of life and property damage occurred in New Orleans, Louisiana since $80 \%$ of the city became flooded and the floodwaters lingered for weeks.

Recently in 2009, typhoon Morakot, a vast, slow-moving tropical storm packing heavy rains, blew through Taiwan on 7 and 8 August. The volume of water it dropped on the island, about $2.5 \mathrm{~m}$, was the highest in five decades. Southern areas of the island encountered more rainfall in one day than they normally observed in one year. As pointed by the Central Weather Bureau of Taiwan, a longer residence time, a wider storm radius and an unsymmetrical structure are three major reasons that the storm caused the record-breaking precipitation over southern Taiwan. The disastrous precipitation triggered widespread flooding, debris flows, and landslides results in more than 670 deaths, 85 missing, 27 bridges collapsed and numerous miles of road washed away, and more than 4.8 billion US dollars economic loss. This disaster could result from a natural hazard and an example of possible outcomes of climate change. As the tremendous increased amounts of precipitation becomes more and more frequent, understanding of the vertical structure of the typhoon precipitating cloud system becomes important issue and needs further investigations.

UHF/L-band wind profiler is sensitive to fluctuation in the radar refractive index or turbulence in clear air as well as the presence of hydrometeors. These hydrometeors are detected at ranges resolved by the wind profiler (Ecklund et al., 1995) yielding the vertical structure of the precipitation system. The advantage of the L-band wind profiler is sensitive to hydrometeors but it does not suffer attenuation in rainfall 
unlike microwave frequencies over $10 \mathrm{GHz}$. Another advantage of the wind profiler is to measure directly the vertical wind component within a convective environment (Gage et al., 1994). Three moment's data of wind profiler, namely, reflectivity, Doppler velocity, and spectral width allow us to retrieve the drop size distribution (DSD) of rain (Williams, 2002).

The melting layer has been identified as a possible source of bias in microwave rainfall retrievals in stratiform regions (Olson et al., 2001). Several researchers [Tokay et al., 1999; Atlas and Williams, 2003; Teshiba et al., 2009] have used wind profiler to reveal details about the vertical structure of precipitating cloud systems associated with mesoscale and large scale precipitating environments. Chandrasekar and Khajonrat (2006) utilized the Tropical Rainfall Measuring Mission (TRMM) satellite Precipitation Radar (PR) for a systematic study of vertical profile of reflectivity (VPR) of hurricanes over North Atlantic, typhoons over North Western Pacific and cyclones over South Indian Ocean. Yang and Houze (1995) indicated that the simulated dynamic and kinematic features, such as rear inflow, of a squall-line type mesoscale convective system are highly sensitive to the microphysical parameterization scheme employed in the model. Wang (2002) further showed in his idealized tropical cyclone (TC) simulations that the cloud structures of the simulated TC are quite sensitive to the cloud microphysics scheme.

As wind profilers, Doppler radar, modeling studies and space-based rainfall retrieval algorithms have gained in sophistication and hence need to properly address the bright band issue. In this paper, effect of bright band on heavy rainfall associated with different typhoons is studied by using an L-band wind profiler and TRMM.

\section{Experimental set-up}

In 2006 the DEGREWIND PCL1300 profiler was deployed at an industrial park $\left(120.38^{\circ} \mathrm{E}, 22.6^{\circ} \mathrm{N}\right)$ close to KaoHsiung city in the southern Taiwan and operated continuously almost every day in order to observe the clear and precipitation echoes in the lower atmosphere. It was then moved to downtown Kao-Hsiung $\left(120.29^{\circ} \mathrm{E}, 22.69^{\circ} \mathrm{N}\right)$ from the spring of 2008. The topography of Taiwan and the location of wind profiler are referred to the Fig. 1 of Pan et al. (2008). The main characteristics of this profiler radar are a $1290-\mathrm{MHz}$ transmitted frequency, with a $4-\mathrm{kW}$ peak pulse power, a $25-\mathrm{kHz}$ pulse repetition frequency, and a 150$\mathrm{m}$ pulse length. One vertical and four oblique beams, with an off-zenith angle of 17 degrees disposed every 90 degrees in azimuth, are swinging continuously to detect the winds. The altitude coverage is from $0.235 \mathrm{~km}$ to $6.543 \mathrm{~km}$ with a 150 $\mathrm{m}$ range resolution. 20 successive Doppler spectra obtained from a 128-point discrete Fourier transform are used to extract the first three moments of the atmospheric echoes. The information about the echo power intensity, radial winds as well as noise level is then deduced. We further incoherently average the derived products in the time domain to present the horizontal winds and the signal-to-noise ratio (SNR) at every $30 \mathrm{~min}$. For more details on technical information of this wind profiler, refer to Heo et al. (2003).

The observations with the L-band wind profiler were carried out fairly continuously since its inception during the end of December 2005. A total of 342 days of wind profiler data are available from 1 January 2006 to 31 December 2006 for analysis. During the observational period, non-availability of the data for a few days was mainly due to system maintenance and system failure. It then was implemented for severe weather observation only since 2007 . Monthly averaged bright band heights from the Tropical Rainfall Measuring Missions' 3A25 monthly product statistical data for the year 2006 are also utilized for present study. For more details on Tropical Rainfall Measuring Mission (TRMM) and data products, refer to Kummerow and Giglio (1994).

Williams et al. (1995) classified wind profiler observed precipitating cloud system as a deep convection, shallow convection, mixed (convection/stratiform), stratiform types. White et al. (2002) proposed a method for bright band height detection algorithm by using the change rate of signal to noise ratio to the altitude and reflectivity profile for the purpose of monitoring the melting level forecasting. Since the physical and dynamical processes of air motion in stratiform clouds are different from convective clouds. And also the vertical profiles of latent heat released in the atmospheric are distinctly different for convective and stratiform precipitating cloud systems. For the present study, we adopted hybrid algorithm based on Williams et al. (1995) and White et al. (2002) the vertical structure of the precipitating cloud systems as deep/shallow convective (without existence of bright band), merged clouds (mixture of convective and stratiform clouds developed due to expansion of convection cloud into a broad hinged/banded cloud system with BB existence below $4.5 \mathrm{~km}$ altitude), Embedded clouds (several relatively high intensity convection cells are formed inside a stratiform cloud system with $\mathrm{BB}$ existence above $5 \mathrm{~km}$ altitude) and weak stratiform (BB presence without convective clouds).

\section{Results and discussions}

Precipitating cloud systems observed during passage of four typhoons over Taiwan and also showery precipitations to diagnose the effect of bright band height on heavy rainfall are the main issues discussed in this study. Two typhoons, namely, Kaemi (200605) and Bopha (200609), invaded Taiwan in the summer of 2006 and the typhoon Jangmi (200815) attacked the island in September of 2008. The deadliest typhoon Morakot (200908) produced copious amounts of rainfall that stroked southern Taiwan in August of 2009. The moderate typhoon Kaemi and the weak typhoon Bopha passed from the north of the observation site with the closest 


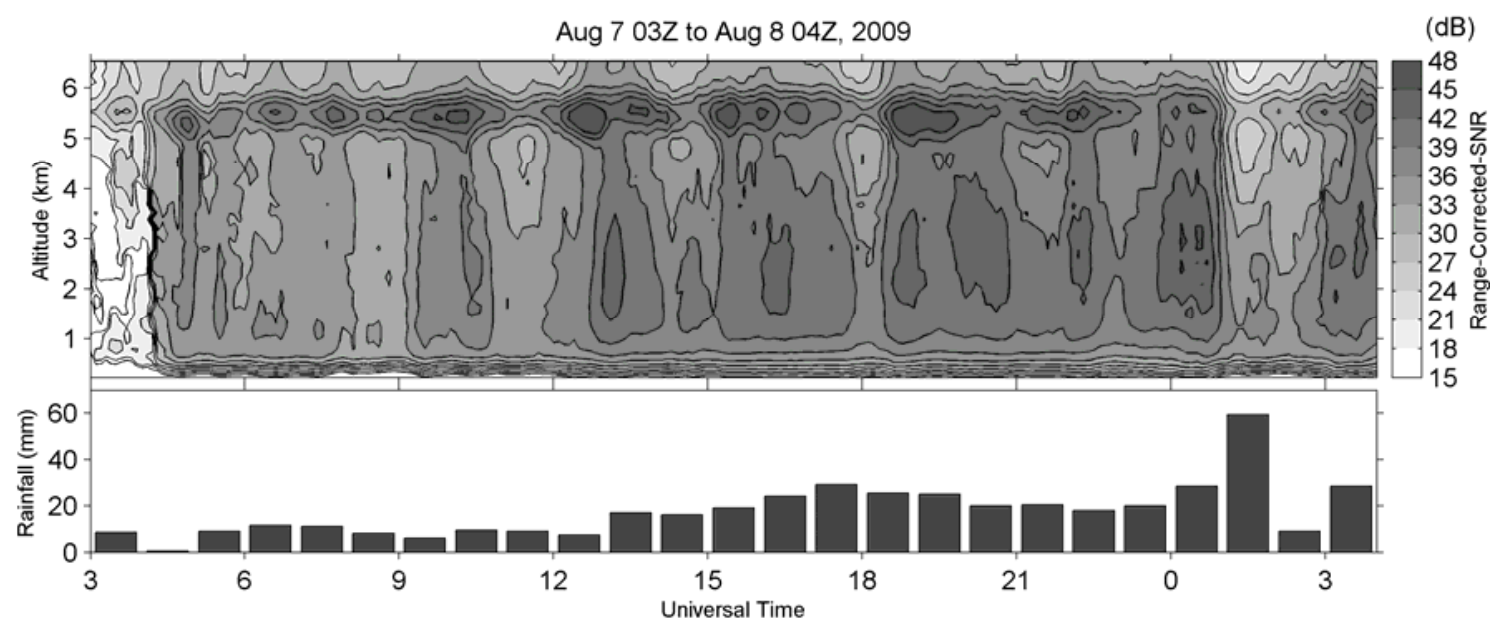

Fig. 1. Observation during the passage of Typhoon Morakot during 7-8 August 2009. (a) Time-height Cross section of range-corrected Signal-to-Noise ratio $(\mathrm{dB})$ and $(\mathbf{b})$ hourly rainfall accumulation at Zuoying. Meteorological Station.

distance of about $60 \mathrm{~km}$ and $20 \mathrm{~km}$, respectively. More information refers to Pan et al. (2008). On the other hand, strong typhoon Jangmi and moderate typhoon Morakot made landfall at the northeastern Taiwan with the distances about $250 \mathrm{~km}$ and $200 \mathrm{~km}$, respectively to the observation site. Due to the big size of these two typhoons, strong precipitations caused by the storms are recorded although their centers are far from the observation site. The shape of the Doppler spectra is characterized by the first three spectral moment information about the hydrometeors in the precipitating cloud systems. The moments yield the reflectivity [Signal-to-Noise Ratio (SNR), dB] of the hydrometeors, the reflectivity-weighted fall speed of the hydrometeors and the variance of the hydrometeor fall speeds within the observing volume. By identifying the appearance of melting layer that causes a "bright band" feature in the echo power profiles, and determining the presence of turbulence or hydrometeors, the vertical structure of the precipitating cloud systems are investigated.

Figure 1a shows wind profiler observation of time-height cross-section of range corrected SNR during the passage of devastating typhoon Morakot. Pronounced bright and is continuously observed around $5.5 \mathrm{~km}$ with increased reflectivity in the area where ice crystals are melting. It is caused when relatively large, low-density ice particles acquire dielectric properties that are more similar to those of water before they collapse into water droplets below the melting layer (Battaglia et al., 2003).

From Fig. 1a one can notice a bright band around $5.5 \mathrm{~km}$ altitude from $04 \mathrm{Z}$ to $01 \mathrm{Z}$ next day. Due to electric power failure, wind profiler operation was stopped at $04 \mathrm{Z}$. Wind profiler observations show that the convective cells embedded in stratiform precipitation quite often appears and it is primarily responsible for heavy rainfall over large region of Taiwan. The precipitation caused by the embedded precipi- tating clouds lasted more than $24 \mathrm{~h}$ with $440 \mathrm{~mm}$ of rainfall accumulated over Zuoying (about $300 \mathrm{~m}$ away from wind profiler site) weather station (Fig. 1b). During the typhoon Morakot invading period, the TRMM satellite also measured excess of $600 \mathrm{~mm}$ of rain in the southern Taiwan (figure not shown).

We have observed 10 typhoon cases that are announced by the Central Weather Bureau of Taiwan since 2006 onwards. Among those 10 typhoons, 4 of them made landfall over Taiwan and produced moderate to heavy rainfall. Figure 2 shows the vertical profiles of SNR of those landed typhoons at the time that the storm centers are at the closest distance to the observation site. In addition, to compare the bright band features of typhoon precipitation, an afternoon shower precipitating clouds (on 14 September 2006) is also used because the background condition in the melting layer may vary significantly for different precipitation events. Wind profiler observational results for those 10 typhoons (the remaining un-landed typhoon cases are not shown in this figure) all show the bright band occurred above $5 \mathrm{~km}$ altitude and, moreover, for typhoon Morakot around $5.5 \mathrm{~km}$. This high bright band altitude phenomenon seems to be common in Taiwan area for all the precipitation associated with typhoon.

Figure 3 shows the vertical profiles of Doppler velocity observed during passage of four landed typhoons and showery precipitation overhead of the wind profiler with the same periods as presented in the Fig. 2.

According to Williams et al. (1995), this figure also features the vertical structure of stratiform rain measured by the wind profiler with Rayleigh scattering from the ice and snow above $6 \mathrm{~km}$ and from rain below $4 \mathrm{~km}$. The showery precipitation profile follows the characteristics have also identified by Fabry and Zawadzki (1995). Nevertheless, rain echoes appear at higher altitudes for typhoon cases than the 


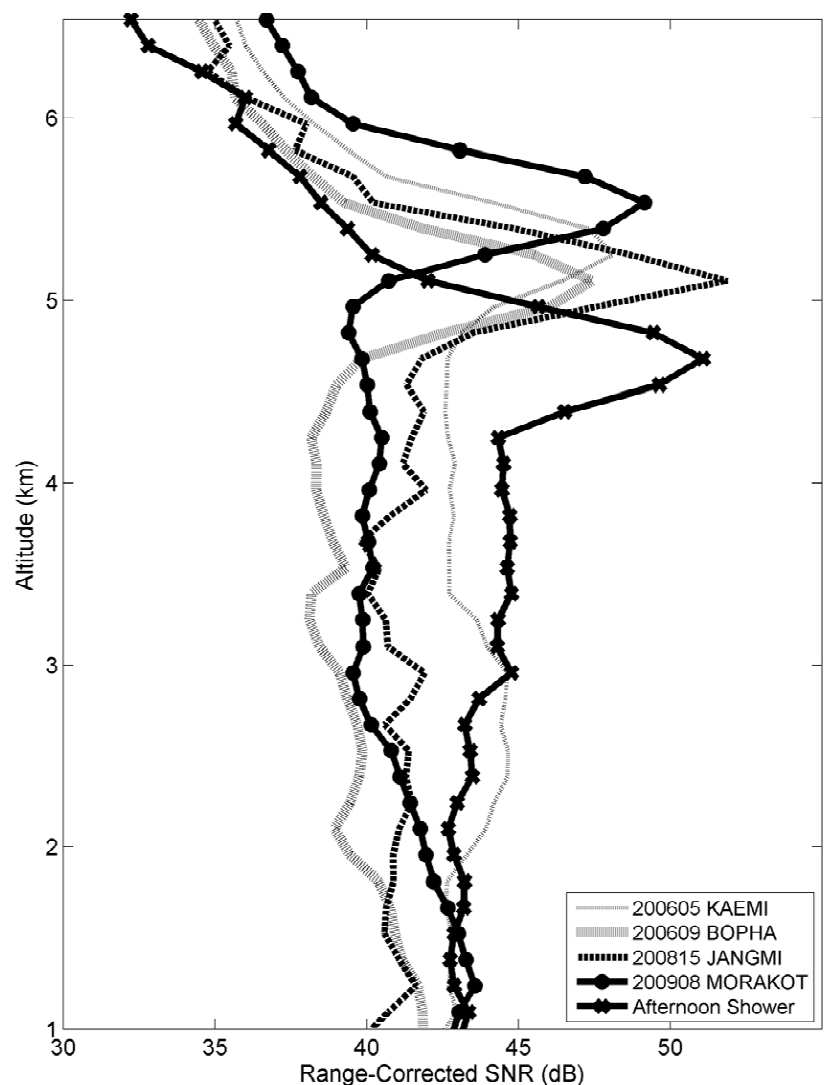

Fig. 2. Vertical Profiles of Signal-to-Noise Ratio [SNR (dB)] Observed during passage of four different typhoons and showery precipitation overhead of the wind profiler.

ordinary shower are noticed in the Fig. 3. In Morakot case, rain forms from $5 \mathrm{~km}$ which is $1 \mathrm{~km}$ higher than shower precipitation. Therefore, one can find that the Doppler velocity gradient (DVG) of hydrometers in the case of Morakot is $5.8 \mathrm{~ms}^{-1} \mathrm{~km}^{-1}$ whereas $3.2 \mathrm{~ms}^{-1} \mathrm{~km}^{-1}$ for shower precipitation. This information may reveal the different acceleration process in the microphysical changes for typhoon and showery rainfall.

In order to investigate the effect of the melting layer/bright band height on typhoon precipitating clouds (observed during July to September), and other types of precipitating clouds (such as Meiyu, showery and winter precipitation clouds), long period wind profiler and TRMM data from January 2006-December 2006 has been analyzed. Wind profiler observed 10 typhoons and 59 other precipitating cloud systems are used for analysis. Figure 4 shows the monthly occurrence of height of the melting layer/bright band and occurrence percentage of (all cloud fractions) convective clouds, merged clouds, embedded clouds and weak stratiform clouds observed during January to December 2006. In the present study we have mainly focused on embedded clouds to know the physical processes responsible for heavy rainfall and bright band height observations from wind profiler (indi-

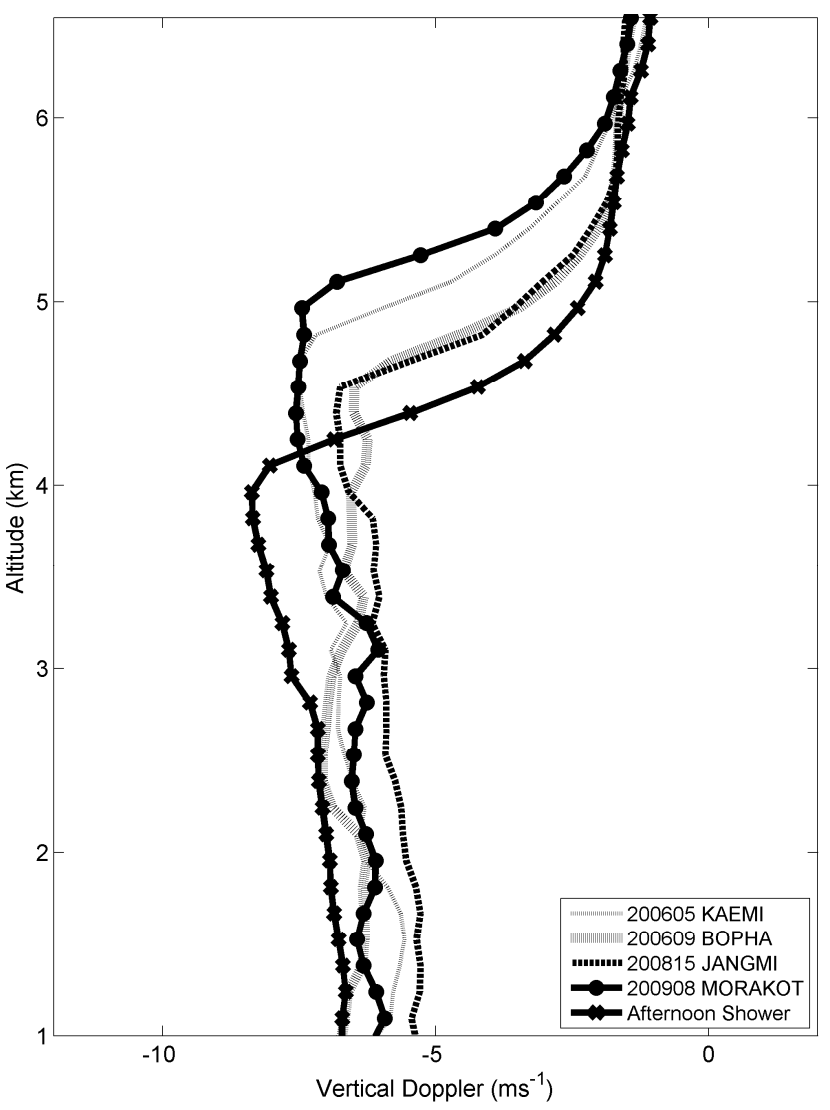

Fig. 3. Vertical profiles of Doppler velocity observed during passage of four typhoons and showery precipitation overhead of the wind profiler.

cates as bar, maximum height of the bright band and also excluding typhoon precipitating clouds) and also from TRMM (indicated as dash with open square symbol) are show in Fig. 4. Wind profiler and TRMM observations show that the monthly occurrences of bright band height are good consistence. Wind profiler observational results show that the bright band height is above $5 \mathrm{~km}$ in the months of July, August and September. During those months, maximum numbers of embedded precipitating clouds are observed with a maximum number of typhoons invaded Taiwan. Chang et al. (2009) reported that the raindrop size distributions (microphysical characteristics) of typhoon systems were neither maritime type convection systems nor continental type convection systems. They also mentioned that the typhoon precipitation behaviors are entirely different when it is passing over ocean and landfall. Also, Wang (2002) conducted a numerical simulation of tropical cyclone precipitation revealed that stratiform cloud bring favorable conditions for developing cumulus cloud, saturated environment and convergence field with stratiform cloud enable convection cloud to have a long life cycle, and to produce continuity high-intensity precipitation and remittent extra-high intensity precipitation. 


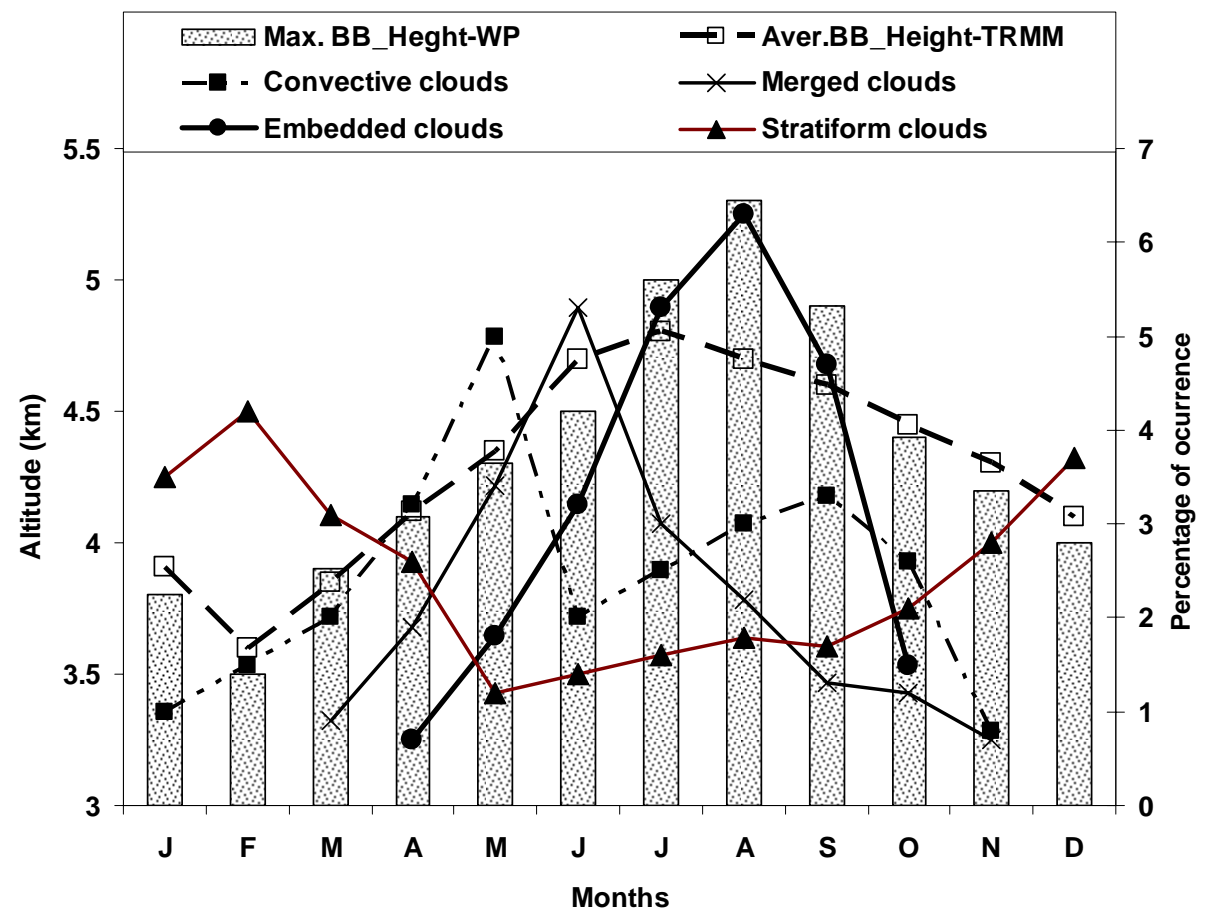

Fig. 4. Monthly occurrence of height of the melting layer/bright band and Occurrence percentage of Convective clouds, Merged clouds, Embedded clouds and Stratiform clouds observed during January to December 2006. Bright band height observations from Wind profiler (indicates as bar, maximum height of the Bright Band and also excluding Typhoon precipitating clouds) and also from Tropical Rainfall Measuring Mission (indicated as dash with open square symbol).

In this study, wind profiler and TRMM observations on typhoons suggest the high bright band altitude associated with stratiform precipitation and accompanied with convection systems has a severe impact on the rainfall over Taiwan.

L-band wind profiler observations during the year 2006 demonstrate that for typhoons the bright band existed above $5 \mathrm{~km}$ and in case of showery precipitation around $4.5 \mathrm{~km}$. The characteristics of the bright band may reveal important cloud microphysical processes. With the topography induced modifications, the cloud and precipitation developments over the mountainous area are expected to be different from those over a coastal region. Cha et al. (2009) made a long term measurement of Micro Rain Radar at two sites (mountain region and a coastal region) in Korea and found that stratiform precipitation was more prevalent at the mountain site, but convective precipitation tended to occur more at the coastal site. As the observation site locates near the coast with more than $35 \mathrm{~km}$ away from the nearest mountain, the topography effect may not play a dominant role in the variation of melting levels. Fabry and Zawadzki (1995) reported that the mixture of ice, air, and water leads to a greater increase in the radar reflectivity than that expected from the change from ice to water. Although the convection takes place in the typhoon precipitation, the thermo-dynamical process shall be different from the convection classified by Williams et al. (1995) that detects no bright band. Moreover, the altitude varia- tion of the melting levels for different typhoons is significant. This may be due to the diverse features of different typhoons with variant tracks, intensities and distances with respect to the wind profiler. We may conclude that the high bright band associated with embedded convection is a common feature of the typhoon precipitation in the island. However, the relation between the elevated melting layer and the embedded convection needs further investigation.

\section{Summary and conclusions}

For the first time, we report that the embedded precipitating clouds posed high bright band that mixed with stratiform and convection rainfalls dominate for the typhoon precipitation over Taiwan. As for the typhoon Morakot, its circulation draws up copious amounts of moisture from the South China Sea into southern Taiwan. The persistent southwesterly flow from the bottom side with strong convection mixed with those hydrometeors supplied by the upper side via the stratiform precipitation that may feature the reason for the heavy amounts of rain over the southern portion of the island. Therefore, the bright band characteristics and the embedded cloud classified in this study are absolutely important in the investigation of typhoon precipitation. Similar precipitation phenomenon/feature may take place at other latitudes that needs further investigations. 
Acknowledgements. This wind profiler is operated by the Environmental Protection Administration (EPA) of Taiwan; R.O.C. C. J. Pan is supported by the NSC of Taiwan, R.O.C. through grant NSC 98-2111-M-008-009.

Topical Editor P. Drobinski thanks K. Gage for his help in evaluating this paper.

\section{References}

Atlas, D. and Williams, C. R.: The Anatomy of a continental tropical convective storm, J. Atmos. Sci., 60, 3-15, 2003.

Battaglia, A., Kummerow, C., Shin, D. B., and Williams, C.: Constraining Microwave Brightness Temperatures by Radar Brightband Observations, J. Atmos. Oceanic Technol., 20, 856-871, 2003.

Cha, J.-W., Chang, K.-H., Yum, S. S., and Choi, Y.-J.: Comparison of the Bright Band Characteristics Measured by Micro Rain Radar (MRR) at a Mountain and a Coastal Site in South Korea, Adv. Atmos. Sci., 26, 211-221, 2009.

Chandrasekar, V. and Khajonrat, D.: Comparison of vertical structures of Hurricanes Typhoons and Cyclones as observed by Spaceborne Precipitation Radar, Proc. of SPIE, 6410, 64100B, doi:10.1117/12.693359, 2006.

Chang, W. Y., Chen Wang, T. C., and Lin, P. L.: The Characteristics of Raindrop Size Distribution and Drop shape Relation in Typhoon Systems in the Western Pacific from 2D-Video Disdrometer and NCU C-Band Polarimetric Radar, J. Atmos. Oceanic Technol., 26, 1973-1993, doi:10.1175/2009JTECHA1236.1, 2009.

Ecklund, W. L., Gage, K. S., and Williams, C. R.: Tropical precipitation studies using a $915 \mathrm{MHz}$ wind profiler, Radio Sci., 30, 1055-1064, 1995.

Fabry, F. and Zawadzki, I.: Long-term radar observation of the melting layer of precipitation and their interpretation, J. Atmos. Sci., 52, 838-851, 1995.

Gage, K. S., Williams, C. R., and Ecklund, W. L.: UHF wind profilers: A new tool for diagnosing tropical convective cloud systems, B. Am. Meteorol. Soc., 75, 2289-2294, 1994.

Heo, B.-H., Jacoby-Koaly, S., Kim, K.-E., Campistron, B., Benech, B., and Jung, E.-S.: Use of the Doppler spectral width to improve the estimation of the convective boundary layer height from UHF wind profiler observations, J. Atmos. Oceanic Technol., 20, 408424, 2003.
Kummerow, C. and Giglio, L.: A passive microwave technique for estimating rainfall and vertical structure information from space. Part I: Algorithm description, J. Appl. Meteor., 33, 3-18, 1994.

Olson, W. S., Bauer, P., Kummerow, C. D., Hong, Y., and Tao, W.: A melting-layer model for passive/active microwave remote sensing applications. Part II: Simulation of TRMM observations, J. Appl. Meteor., 40, 1164-1179, 2001.

Pan, C. J., Lai, H. C., Yang, S. S., Reddy, K. K., and Chang, S.-C.: Wind profiler radar investigation on typhoonorography interaction, Geophys. Res. Lett., 35, L24812, doi:10.1029/2008GL036368, 2008.

Teshiba, M. S., Chilson, P. B., Ryzhkov, A. V., Schuur, T. J., and Palmer, R. D.: A combined Wind Profiler and Polarimetric Weather Radar Method for the investigation of Precipitation and vertical velocities, J. Atmos. Oceanic Technol., 26, 1940-1954, doi:10.1175/2008JTECHA11021, 2009.

Tokay, A., Short, D. A., Williams, C. R., Ecklund, W. L., and Gage, K. S.: Tropical rainfall associated with convective and stratiform clouds: Intercomparison of disdrometer and profiler measurements, J. Appl. Meteorol., 38, 302-320, 1999.

Wang, Y.: An explicit simulation of tropical cyclones with a triply nested movable mesh primitive equation model: TCM3. Part II: Model refinements and sensitivity to cloud microphysics parameterization, Mon. Weather Rev., 130, 3022-3036, 2002.

White, A. B., Gottas, D. J., Strem, E. T., Ralph, F. M., and Neiman, P. J.: An automated bright band height detection algorithm for use with Doppler radar spectral moment, J. Atmos. Oceanic Technol., 19, 687-697, 2002.

Williams, C. R., Ecklund, W. L., and Gage, K. S.: Classification of precipitating clouds in the tropics using $915-\mathrm{MHz}$ wind profilers, J. Atmos. Oceanic Technol., 12, 996-1012, 1995.

Williams, C. R.: Simultaneous ambient air motion and raindrop size distributions retrieved from UHF vertical incident profiler observations, Radio Sci., 37(2), 1024, doi:10.1029/2000RS002603, 2002.

Wu, C.-C. and Kuo, Y.-H.: Typhoon affecting Taiwan: current understanding and future challenges, B. Am. Meteorol. Soc., 80, 67-80, 1999.

Yang, M.-J. and Houze Jr., R. A.: Sensitivity of squall-line rear inflow to ice microphysics and environmental humidity, Mon. Weather Rev., 123, 3175-3193, 1995. 